\title{
Measured and Calculated Integral Reactivity of Control Rods in RSG- GAS First Core
}

\author{
Wahid Luthfi $^{1 *}$, Surian Pinem ${ }^{1}$, Donny Hartanto ${ }^{2,3}$, Lily Suparlina ${ }^{1}$, Dwi Haryanto ${ }^{4}$ \\ ${ }^{I}$ Research and Technology Center for Nuclear Reactor Safety, Research Organization for Nuclear Energy, National Research and Innovation Agency, \\ Building 80th Science and Technology Research Center (PUSPIPTEK), Serpong Nuclear Area, Setu, South Tangerang, Banten, Indonesia \\ ${ }^{2}$ Department of Mechanical and Nuclear Engineering, University of Sharjah, P.O. BOX 27272, Sharjah, United Arab Emirates \\ ${ }^{3}$ Nuclear Energy System Simulation and Safety Research Group, Research Institute of Sciences and Engineering, University of Sharjah, P.O. BOX \\ 27272, Sharjah, United Arab Emirates \\ ${ }^{4}$ Directorate of Nuclear Facility Management, Deputy for Research and Innovation Infrastructure, National Research and Innovation Agency, Building \\ 80th Science and Technology Research Center (PUSPIPTEK), Serpong Nuclear Area, Setu, South Tangerang, Banten, Indonesia
}

\section{ARTICLE INFO}

Article history:

Received: 18 February 2022

Received in revised form: 1 March 2022

Accepted: 2 March 2022

\section{Keywords:}

Control rods worth

RSG-GAS

Serpent 2 code

Reactivity

First core

\begin{abstract}
A B S T R A C T
The control rod worth is one of the important parameters for the operation of a nuclear reactor. Proper measurement and calculation of the control rod worth are essential for the safe reactor operation under normal and transient conditions that are initiated by a postulated event such as stuck rod, control rods ejection, etc. This paper presents calculation results of integral reactivity of the RSG-GAS research reactor first core and its comparison with the experimental data. Calculations were performed using the continuous energy transport code Serpent 2 with ENDF/BVIII.0 nuclear data. Integral reactivity measurement was done by compensating method with control rod bank, regulating rod, and reactivity meter. Calculations were carried out for each method used in control rod measurement data with an aim to validate calculated results to experimental data. Compared with the measured experiment data, there are no significant differences in calculation results of integral reactivity. The maximum difference of the control rod's total reactivity is $1.26 \%$ compared to the measurement carried out by compensating method with regulating rod.
\end{abstract}

(C) 2022 Tri Dasa Mega. All rights reserved.

\section{INTRODUCTION}

The RSG-GAS is an open pool-type research reactor, cooled and moderated by light water, and uses a beryllium reflector that operates at a nominal power of $30 \mathrm{MW}$. The RSG-GAS reactor core initially uses plate-type $\mathrm{U}_{3} \mathrm{O}_{8}-\mathrm{Al}$ fuel and then converted to plate-type $\mathrm{U}_{3} \mathrm{Si}_{2}-\mathrm{Al}$ fuel with the same density of $2.96 \mathrm{gU} / \mathrm{cc}$ and $19.75 \%$ enriched uranium. The RSG-GAS reactor is designed for research, material testing by irradiation, and radioisotope production.

\footnotetext{
*Corresponding author

Email: wahid@batan.go.id

DOI: $10.17146 / \mathrm{tdm} .2022 .24 .1 .6593$
}

An important part of the neutronic experiment is to measure several parameters related to the safety of nuclear reactor operation, such as the control rod worth and its Integral reactivity[1-3]. Integral reactivity curves were also used for reactor transient operation analysis[4-6]. For this reason, it is vital to determine a proper calculation method and measurement in determining the integral reactivity curves of the control rod. Many well-developed Monte Carlo neutron transport codes are used for the operation and safety analysis of research reactors [7]. Therefore, it is necessary to validate the code by the experimental data. The RSSG-GAS reactor performed several measurements during reactor commissioning, and this data could be used for validation. The criticality calculation of the RSG- 
GAS core has been widely used to verify several neutronics codes[8-11]. In this paper, the integral reactivity curves will be evaluated using Serpent 2 program with the latest nuclear data ENDF/BVIII.0[12]. For this case, RSG GAS first core data will be used when the fuel is still fresh (unburn). The measurement method used is based on positive to negative reactivity compensation. The compensation method uses two additional methods: single control $\operatorname{rod}(\mathrm{CR})$ calibration with reactivity compensation by CR bank, and single CR calibration with reactivity compensation by regulating rod. In addition to the compensation method, a positive reactivity release from the reactivity meter is also used. The goal of this research is to validate calculated results to the experimental data. The evaluated control rods are JDA-06 and JDA-03, both will be compared with the measured experimental results.

\section{RSG-GAS FIRST CORE}

The RSG-GAS reactor achieved its first criticality on 29 July 1987 with its first core containing 12 standard fuel elements, 6 control elements, and 39 beryllium, with a nominal power of 10.7 MW. Fuel element contains $\mathrm{U}_{3} \mathrm{O}_{8}-\mathrm{Al}$ with a uranium density of $2.96 \mathrm{gU} / \mathrm{cm} 3$. The control elements consist of fork-type control rod absorbers, Ag-In-Cd alloy. The number of fuel plates in the standard fuel element is 21 plates and 15 plates for the control element, with $\mathrm{AlMg}_{2}$ as cladding[8]. Some of the important parameters used in the calculations are shown in Table 1, the first core configuration or RSG-GAS is shown in Figure 1, and fuel element layouts are presented on Figure 2.

\section{INTEGRAL CONTROL ROD WORTH EXPERIMENTS}

The RSG-GAS reactor is critical at low power source-free condition by positioning bank-rods in critical positions. The calibrated control rod is in fully inserted condition. In general, after waiting for $10 \mathrm{~s}$ for transient during its insertion, the reactor is compensated by the control rod bank. Each part of the calibrated control rod is then withdrawn with the reactivity of about $10-20$ cents that will be compensated by the control rod bank, and 20 cents if regulating rod is used as a compensator. Hence, when using the compensation method by the control bank, the position of the control rod to be calibrated is initially fully inserted into the core (at $0 \mathrm{~mm}$ ) while the other 5 control rods are set as the bank position. The withdrawal of the control rod is carried out step by step and each withdrawal step is compensated by the control bank to make the reactor critical at low power. Withdrawals are carried out until the calibrated control rod position is $600 \mathrm{~mm}$.

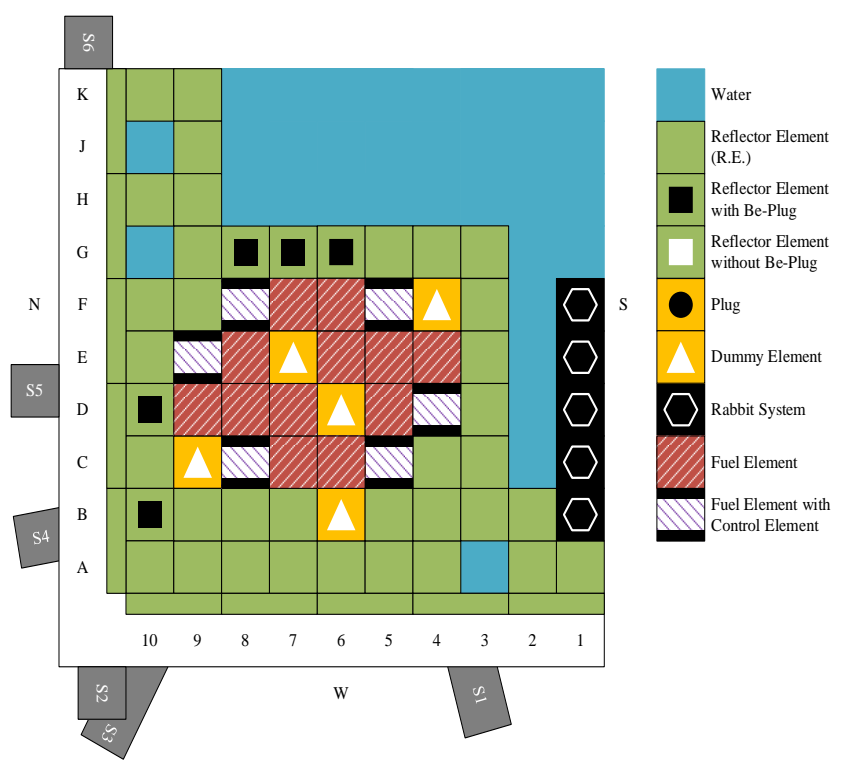

Fig. 1. RSG-GAS first core configuration[10]

The compensation by regulating rod method starts with calibrated control rod positioned on fully inserted $(0 \mathrm{~mm})$ and the regulating rod fully up position $(600 \mathrm{~mm})$ while the other 4 control rods are in a fixed position to achieve critical condition at low power source-free condition. In this case, the control rod at the $0 \mathrm{~mm}$ position is called positive compensation rod and the $600 \mathrm{~mm}$ position is called negative compensation rod. The positive compensation rod is carried out first, and then the negative compensation rod. This step is carried out step by step until the positive compensation rod is at $600 \mathrm{~mm}$ (fully up) and the negative compensation $\operatorname{rod}$ is at $0 \mathrm{~mm}$ (fully down). If the negative compensation rod position cannot be positioned at fully down, then the reactivity is determined by the reactivity meter or by rod drop method.

RSG-GAS control rods are identified by code numbers, for example, JDA-01 is a control rod located on grid E-9. Data from JDA-06 control rod measurement results using compensated by bank methods and reactivity meter are shown in Table 2 and Table 3. Measured data JDA-03 from compensated by control bank and regulating rod method are shown in Table 4 and Table 5. 
Table 1. Geometry and composition of RSG-GAS first core[8]

\begin{tabular}{lcc}
\hline & Standard fuel & Control element \\
\hline Fuel/Control Element Dimension $(\mathrm{mm})$ & $77.1 \times 81 \times 600$ & $77.1 \times 81 \times 600$ \\
Number of meat plates each element & 21 & 15 \\
Uranium density $\left(\mathrm{g} / \mathrm{cm}^{3}\right) / \mathrm{U}-235$ enrich. & $2.96 / 19.75 \%$ wo & $2.96 / 19.75 \%$ wo \\
U-235 loading $(\mathrm{g})$ & 250 & 178.6 \\
Number of fuel elements in core & 12 & 6 \\
Fuel and absorber material & $\mathrm{U}_{3} \mathrm{O}_{8}-\mathrm{Al}$ & $\mathrm{Ag}-\mathrm{In}-\mathrm{Cd}$ \\
Cladding material & $\mathrm{AlMg}_{2}$ & $\mathrm{SUS}-321$ \\
\hline
\end{tabular}
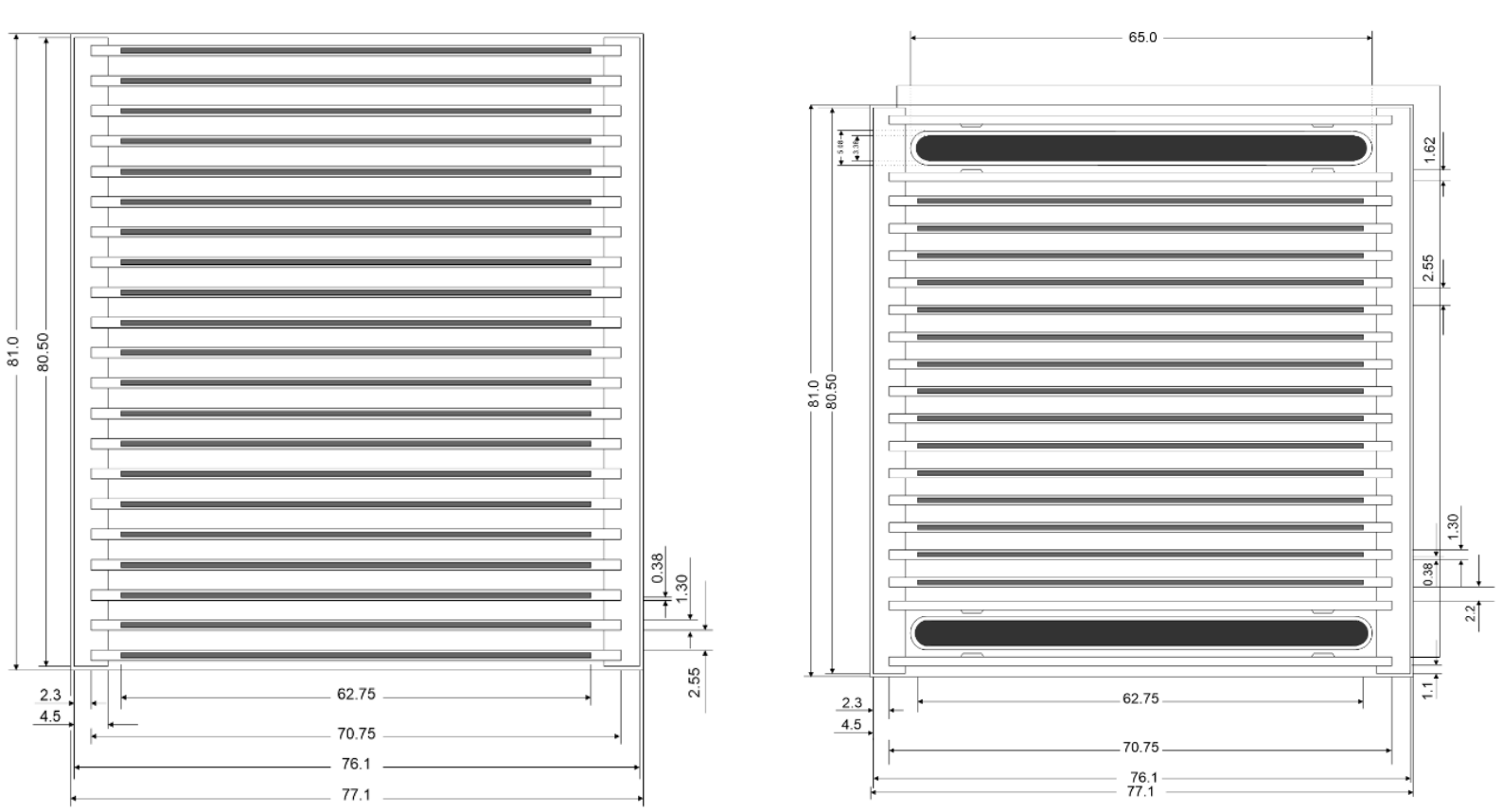

Fig. 2. Layout of standard fuel element (left) and control element (right)

Table 2. Control rod position data of JDA-06 compensated by bank[11]

\begin{tabular}{cccc}
\hline Control rod & $\begin{array}{c}\text { Position in } \\
\text { the core }\end{array}$ & Control inserted $(\mathrm{mm})$ & $\begin{array}{c}\text { Number of } \\
\text { steps }\end{array}$ \\
\hline JDA-06 & C-8 & $0-600$ & 22 \\
JDA-01 & E-9 & $291-207$ & 22 \\
JDA-03 & F-8 & $290-207$ & 22 \\
JDA-04 & F-5 & $291-207$ & 22 \\
JDA-05 & C-5 & $290-207$ & 22 \\
JDA-07 & D-4 & $292-207$ & 22 \\
\hline
\end{tabular}

Table 3. Control rod calibration position data of JDA-06 by reactivity meter[11]

\begin{tabular}{cccc}
\hline Control rod & $\begin{array}{c}\text { Position in } \\
\text { the core }\end{array}$ & $\begin{array}{c}\text { Control inserted } \\
(\mathrm{mm})\end{array}$ & $\begin{array}{c}\text { Number of } \\
\text { steps }\end{array}$ \\
\hline JDA-06 & C-8 & $0-600$ & 41 \\
JDA-01 & E-9 & $291-207$ & 41 \\
JDA-03 & F-8 & $291-207$ & 41 \\
JDA-04 & F-5 & $290-207$ & 41 \\
JDA-05 & C-5 & $290-207$ & 41 \\
JDA-07 & D-4 & $290-207$ & 41 \\
\hline
\end{tabular}


Table 4. Control rod calibration position data of JDA-03 compensated by bank[11]

\begin{tabular}{cccc}
\hline Control rod & $\begin{array}{c}\text { Position in } \\
\text { the core }\end{array}$ & Control inserted (mm) & $\begin{array}{c}\text { Number of } \\
\text { steps }\end{array}$ \\
\hline JDA-03 & F-8 & $0-600$ & 22 \\
JDA-01 & E-9 & $293-214$ & 22 \\
JDA-06 & C-8 & $293-214$ & 22 \\
JDA-04 & F-5 & $293-214$ & 22 \\
JDA-05 & C-5 & $293-214$ & 22 \\
JDA-07 & D-4 & $293-214$ & 22 \\
\hline
\end{tabular}

Table 5. Control rod calibration position data of JDA-03 compensated by regulating rod[11]

\begin{tabular}{cccc}
\hline Control rod & $\begin{array}{c}\text { Position in } \\
\text { the core }\end{array}$ & Control inserted $(\mathrm{mm})$ & $\begin{array}{c}\text { Number of } \\
\text { steps }\end{array}$ \\
\hline JDA-03 & F-8 & $0-600$ & 22 \\
JDA-01 & E-9 & $243-243$ & - \\
JDA-06 & C-8 & $600-75$ & 22 \\
JDA-04 & F-5 & $243-243$ & - \\
JDA-05 & C-5 & $243-243$ & - \\
JDA-07 & D-4 & $243-243$ & - \\
\hline
\end{tabular}

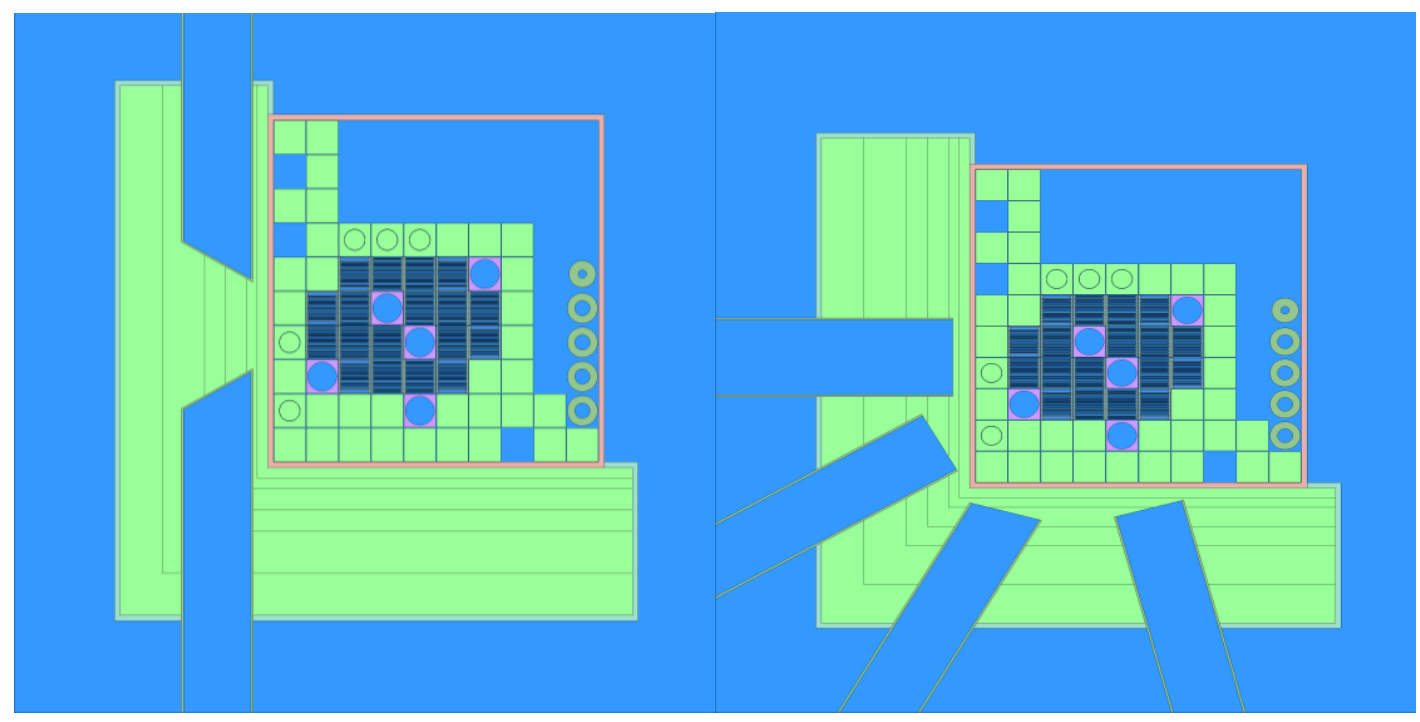

Fig. 3. Serpent model of the RSG-GAS first core

\section{METHODOLOGY}

The Serpent 2 core model of RSG-GAS first core from the previous study was used, and the sixbeam tubes in the reflector block region were also included[8, 13]. These six-beam tubes model with all 12 standard fuel elements and 6 control elements, surrounded by 39 beryllium reflectors could be seen in Figure 3. Moreover, the thermal scattering libraries $\mathrm{S}(\alpha, \beta)$ for hydrogen in the light water and beryllium as metal were included in the calculation. The temperature of all materials in the core was 300 $K$. The criticality calculation by Serpent 2 code was carried out using 400,000 neutron histories per cycle, and the total number of cycles is 500 with 100 inactive cycles, providing the standard deviation of the effective multiplication factor $\left(\mathrm{k}_{\text {eff }}\right)$ less than 10 pcm.
The integral reactivity of the control rod depends on its drawn distance from the core. Calculated reactivity is determined from $\mathrm{k}_{\mathrm{eff}}$ for each control rod withdrawal. The integral control rod value is the sum-up reactivity worth of the control rod at a certain step of withdrawal. Same as the experiment, integral control rod worth is calculated once the control rod is pulled from the bottom of the core, then it is gradually pulled up and ended once it is at the top of the core.Criticality calculations carried out with Serpent 2 also calculate the effective delayed neutron fraction, $\beta \mathrm{j}$ that compared to $\beta \mathrm{j}$ design value used by reactivity meter. 


\section{RESULTS AND DISCUSSION}

The calculated results and measurement of JDA-06 integral reactivity using the compensated method with control rod bank and reactivity meter are shown in Figure 4 and Figure 5.

The total reactivity worth of the JDA-06 control rod is shown in Table 6. The difference in the calculation reactivity value compared to measurement is caused by several errors embedded in the measurement. In measuring the reactivity using compensated by control rod bank, the error from each reactivity response is $\pm 0.5 \mathrm{cent} / \mathrm{step}$ and because in this measurement, there are 22 steps, the error is about \pm 11 cent. In the measurement using the reactivity meter, the error caused by the reactivity response and the estimation of criticality is about
0.25 cent/step. In the measurement with the reactivity meter, there are 41 steps, so the total error is \pm 30 cents. Based on the results in Table 6 , there is a difference of $0.61 \%$ in Serpent 2 calculation result compared to measurements data using compensated by control rod bank method and $0.04 \%$ when compared to the reactivity meter.

On the other hand, Serpent 2 calculation results are embedded with its statistical uncertainty that manifested as a deviation standard that could be seen increasing in each figure as control rods pulled out from the core. This increase is correlated to a mathematical calculation that sums up calculated reactivity from each step of the control rod withdrawn.

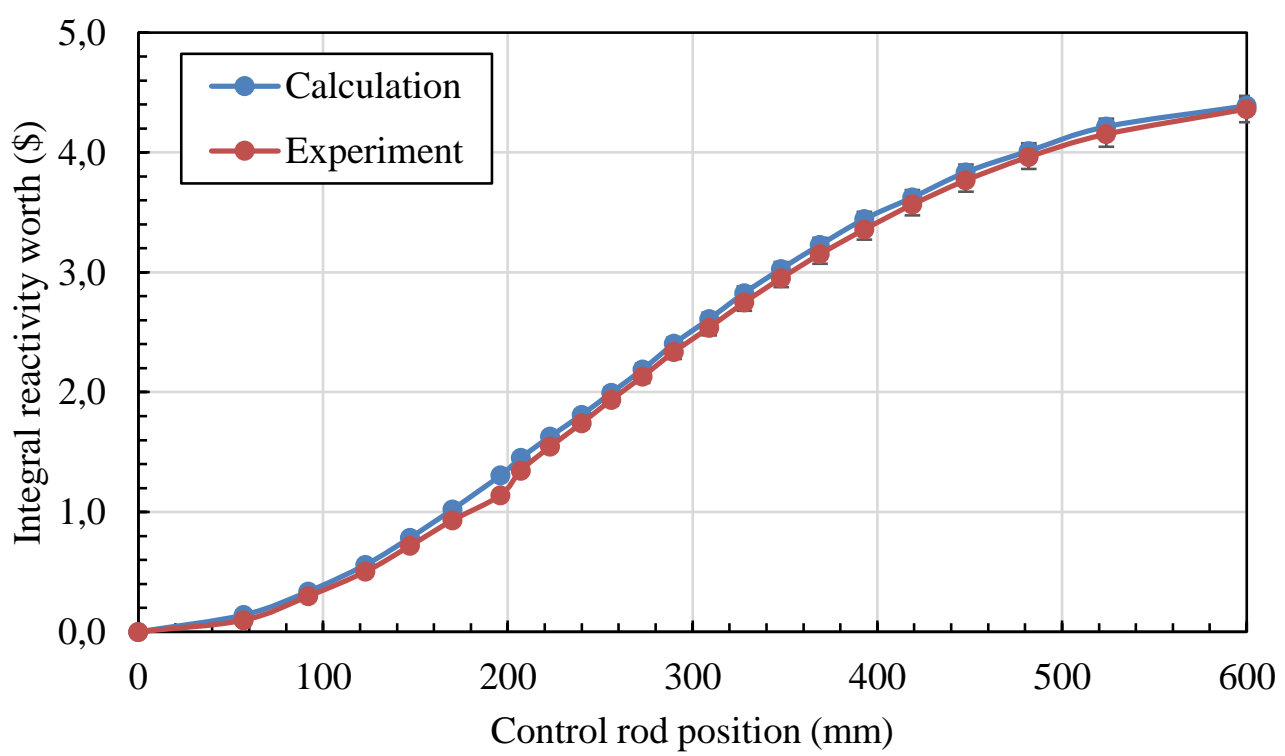

Fig. 4. Integral reactivity of JDA-06 compensated by control rod bank

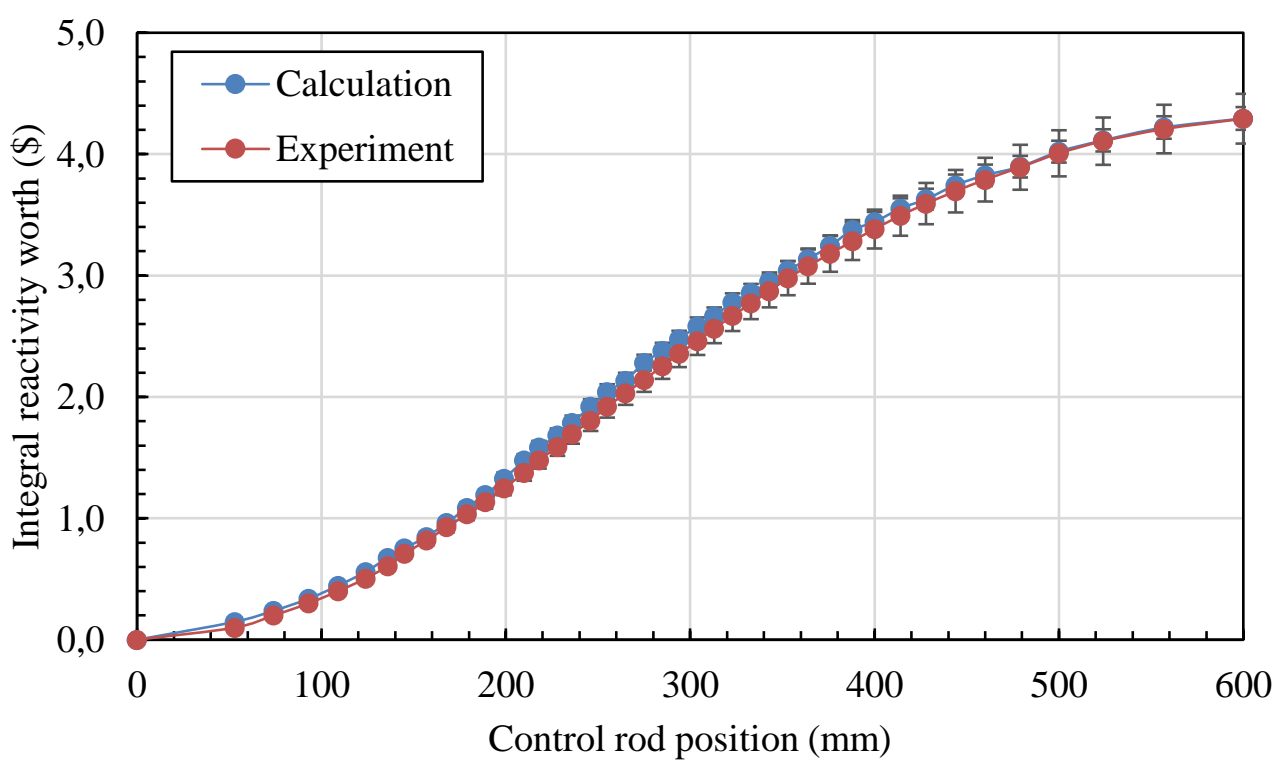

Fig. 5. Integral reactivity of JDA-06 by reactivity meter. 
Table 6. JDA-06 total control rod worth

\begin{tabular}{ccccc}
\hline \multicolumn{4}{c}{ Control rod reactivity worth JDA-06 (\$) } \\
\hline $\begin{array}{c}\text { Compensated by } \\
\text { control rod bank } \\
\text { method }\end{array}$ & $\begin{array}{c}\text { Calculation by } \\
\text { Serpent } 2\end{array}$ & $\begin{array}{c}\text { Reactivity meter } \\
\text { method }\end{array}$ & $\begin{array}{c}\text { Calculation by } \\
\text { Serpent } 2\end{array}$ & Stable period method \\
\hline $4.363 \pm 0.11$ & $\begin{array}{c}4.389 \pm 0.61 \\
(-0.61 \%)\end{array}$ & $4.292 \pm 0.30$ & $4.294 \pm 0.046$ & $4.37 \pm 0.42$ \\
& & & $(0.04 \%)$ & \\
\hline
\end{tabular}

The calculated and measured results of JDA-03 integral reactivity using compensation with control rod banks and regulating rods are shown in Figure 6 and Figure 7. Based on Figure 6, the calculation results with Serpent 2 are very close to the measurement. The integral reactivity worth with compensated by regulating rod as shown in Figure 7 have several differences but still within Serpent calculation result range of error. The error carried by the experiment of compensated by regulating rod is that the positive and negative compensation values are not identic so that when the positive compensation control rod is fully up, then the negative compensation is not fully down.

The JDA-03 reactivity worth is presented in Table 7 and it can be seen that the calculation with
Serpent has a difference of $0.82 \%$ compared to measurements using compensated by control rod bank method and $1.26 \%$ compared to compensated by regulating rod method. Based on these results, it shows that in determining the integral reactivity curves of the RSG-GAS control rod, Serpent 2 gives a minimum amount of deviation to experimental data, especially in these first core of RSG-GAS. The general difference that occurs when comparing this result to experimental results of the control rod is the inaccuracy of the position of the absorber in the control rod that is not precisely parallel to the upper and lower limits of the fuel element when fully withdrawn and fully inserted.

Table 7. JDA-03 total control rod worth

\begin{tabular}{cccc}
\hline \multicolumn{4}{c}{ Control rod reactivity worth JDA-03 $(\$)$} \\
\hline $\begin{array}{c}\text { Compensated } \\
\text { by control rod } \\
\text { bank method }\end{array}$ & $\begin{array}{c}\text { Calculation by } \\
\text { Serpent } 2\end{array}$ & $\begin{array}{c}\text { Compensated } \\
\text { by regulating } \\
\text { rod method }\end{array}$ & Calculation by Serpent 2 \\
\hline $4.227 \pm 0.11$ & $4.242 \pm 0.068$ & $4.178 \pm 0.11$ & $4.231 \pm 0.066$ \\
& $(0.82 \%)$ & & $(1.26 \%)$ \\
\hline
\end{tabular}

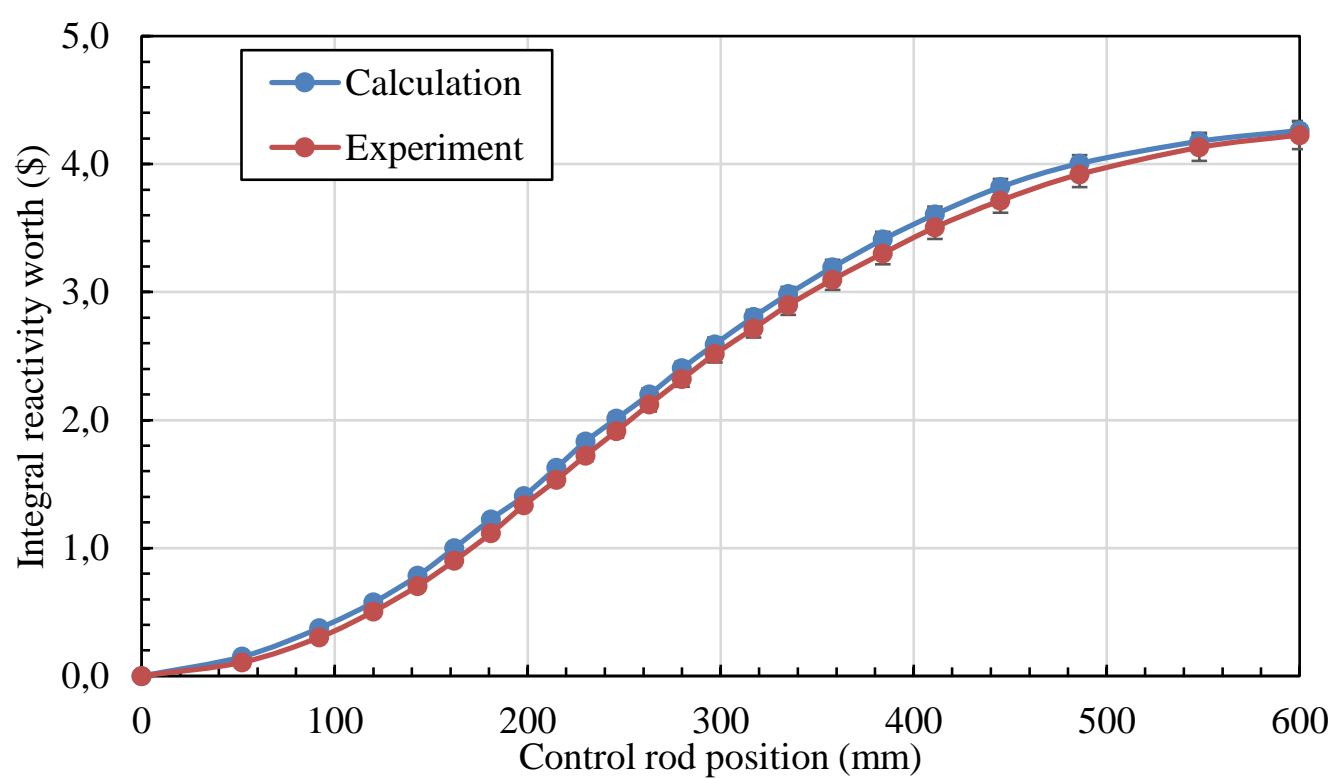

Fig. 6. Integral reactivity worth of JDA- 03 compensated by control rod bank 


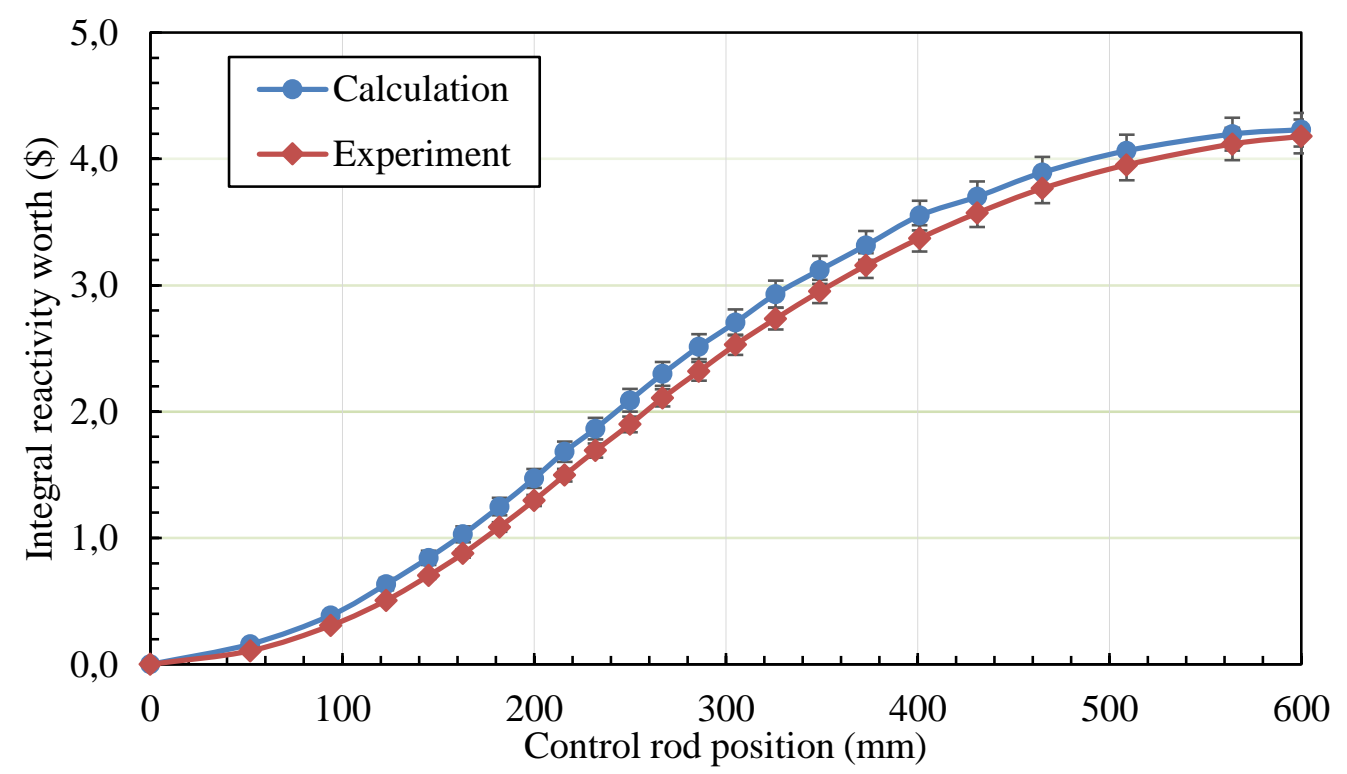

Fig. 7. Integral reactivity worth of JDA- 03 compensated by regulating rod

\section{CONCLUSION}

Evaluation of the integral control rod worth based on the measurement results and the calculation carried out by Serpent 2 for RGS-GAS first core has been done. The calculation is carried out as detailed as measurement steps using the compensation and reactivity meter methods. The calculation results of the integral reactivity worth are in good agreement with the experimental results. The maximum difference between the calculation and measurement of control rod worth is $1.26 \%$, which is compared to the measurement with the compensation with regulating rod method. Therefore, it is concluded that Serpent 2 can be used in the future to determine the integral control rod worth and its reactivity calculation of the RSG-GAS reactor.

\section{ACKNOWLEDGMENT}

Our thanks to the Head of Research and Technology Center for Nuclear Reactor Safety, Dr. Syaiful Bakhri, as well as the staff of Reactor Physics and Technology Division of Research and Technology Center for Nuclear Reactor Safety for their cooperation, and staff members of the RSGGAS Multipurpose Reactor for conducting the experiments.

\section{AUTHOR CONTRIBUTION}

Wahid Luthfi: Data Curation, Visualization, Writing Original Draft, Review, and Editing. Surian Pinem: Conceptualization, Validation, Formal Analysis, Writing Original Draft \& Review. Donny Hartanto: Methodology, Calculation, Data Curation, Formal Analysis, Writing Review. Lily
Suparlina: Conceptualization, Writing Review. Dwi Haryanto: Data Curation, Writing Review.

\section{REFERENCES}

1. Torabi M., Lashkari A., Masoudi S.F., Bagheri S. Neutronic Analysis of Control Rod Effect on Safety Parameters in Tehran Research Reactor. Nucl. Eng. Technol. 2018. 50(7):1017-23.

2. Yari M., Lashkari A., Masoudi S.F., Hosseinipanah M. Three Dimensional Analysis of Temperature Effect on Control Rod Worth in TRR. Nucl. Eng. Technol. 2018. 50(8):126676.

3. Nasrazadani Z., Ahmadi A., Khorsandi J. Measurement of Safety Rods Reactivity Worth by Advanced Source Jerk Method in HWZPR. Nucl. Eng. Technol. 2019. 51(4):963-7.

4. Surian P., Sembiring T.M., Tukiran S. Reactivity Insertion Accident Analysis During Uranium Foil Target Irradiation in the RSGGAS Reactor Core. Nucl. Technol. Radiat. Prot. 2020. 35(3):1-7.

5. Surbakti T., Pinem S., Suparlina L. Dynamic Analysis on the Safety Criteria of the Conceptual Core Design in MTR-type Research Reactor. Atom Indones. 2018. 44(2):89-97.

6. Pinem S., Sembiring T.M., Liem P.H. Neutronic and Thermal-Hydraulic Safety Analysis for the Optimization of the Uranium Foil Target in the RSG-GAS Reactor. Atom Indones. 2016. 42(3):123-8.

7. Shchurovskaya M. V., Alferov V.P., Geraskin N.I., Radaev A.I., Naymushin A.G., Chertkov Y.B., et al. Control Rod Calibration Simulation Using Monte Carlo Code for the IRT-type Research Reactor. Ann. Nucl. Energy. 2016. 
96:332-43.

8. Hartanto D., Liem P.H. Analysis of the First Core of the Indonesian Multipurpose Research Reactor RSG-GAS Using the Serpent Monte Carlo Code and the ENDF/B-VIII.0 Nuclear Data Library. Nucl. Eng. Technol. 2020. 52(12):2725-32.

9. Liem P.H., Surbakti T., Hartanto D. Kinetics Parameters Evaluation on the First Core of the RSG-GAS (MPR-30) Using Continuous Energy Monte Carlo Method. Prog. Nucl. Energy. 2018. 109(June):196-203.

10. Surbakti T., Pinem S., Sembiring T.M., et.al. Calculation of Control Rods Reactivity Worth of RSG-GAS First Core Using Deterministic and Monte Carlo Methods. Atom Indones.
2019. 45(2):69-79.

11. Liem P.H., Zuhair, Hartanto D. Sensitivity and Uncertainty Analysis on the First Core Criticality of the RSG GAS Multipurpose Research Reactor. Prog. Nucl. Energy. 2019. 114(February):46-60.

12. Leppänen J. et al. The Serpent Monte Carlo Code: Status, Development and Applications in 2013. Ann. Nucl. Energy. 2015. 82:142-150.

13. Sembiring T.M., Pinem S., Hartanto D., Liem P.H. Analysis of the Excess Reactivity and Control Rod Worth of RSG-GAS Equilibrium Silicide Core Using Continuous-Energy Monte Carlo Serpent2 Code. Ann. Nucl. Energy. 2021. 154:108107. 